\title{
BMJ Open Kanuka honey versus aciclovir for the topical treatment of herpes simplex labialis: a randomised controlled trial
}

Alex Semprini, ${ }^{\oplus 1}$ Joseph Singer, Irene Braithwaite, ${ }^{\oplus 1}$ Nick Shortt, ${ }^{1}$
Darmiga Thayabaran, ${ }^{1}$ Melanie McConnell, ${ }^{2}$ Mark Weatherall, ${ }^{3}$ Richard Beasley ${ }^{1}$

To cite: Semprini A, Singer J, Braithwaite I, et al. Kanuka honey versus aciclovir for the topical treatment of herpes simplex labialis: a randomised controlled trial. BMJ Open 2019;9:e026201. doi:10.1136/ bmjopen-2018-026201

- Prepublication history for this paper is available online. To view these files, please visit the journal online (http://dx.doi. org/10.1136/bmjopen-2018026201).

Received 4 September 2018 Revised 17 April 2019 Accepted 17 April 2019

Check for updates

(C) Author(s) (or their employer(s)) 2019. Re-use permitted under CC BY-NC. No commercial re-use. See rights and permissions. Published by BMJ.

${ }^{1}$ Medical Research Institute of New Zealand, Wellington, New Zealand

${ }^{2}$ Victoria University of Wellington, Wellington, New Zealand

${ }^{3}$ University of Otago Wellington, Wellington, New Zealand

Correspondence to

Dr Alex Semprini;

alex.semprini@mrinz.ac.nz

\section{ABSTRACT}

Objective To compare New Zealand medical grade kanuka honey with topical aciclovir for the treatment of herpes simplex labialis.

Design Prospective parallel randomised controlled openlabel superiority trial.

Setting 76 community pharmacies across New Zealand between 10 September 2015 and 13 December 2017.

Participants 952 adults randomised within the first

72 hours of a herpes simplex labialis episode.

Interventions Random assignment 1:1 to either $5 \%$ aciclovir cream or medical grade kanuka honey $(90 \%) /$ glycerine (10\%) cream, both applied five times daily. Outcome measures The primary outcome was time from randomisation to return to normal skin (stage 7). Secondary outcomes included time from randomisation to stage 4 (open wound), time from stage 4 to 7 , maximal pain, time to pain resolution and treatment acceptability. Results Primary outcome variable: Kaplan-Meier-based estimates $(95 \% \mathrm{Cl})$ for the median time in days for return to normal skin were 8 (8 to 9 ) days for aciclovir and 9 (8 to 9$)$ for honey; HR $(95 \% \mathrm{Cl}) 1.06$ (0.92 to 1.22$), p=0.56$. There were no statistically significant differences between treatments for all secondary outcome variables. No related serious adverse events were reported.

Conclusion There was no evidence of a difference in efficacy between topical medical grade kanuka honey and $5 \%$ aciclovir in the pharmacy-based treatment of herpes simplex labialis.

Trial registration number ACTRN12615000648527;Postresults

\section{INTRODUCTION}

Herpes simplex virus (HSV) is a pervasive human infection. The global prevalence is reported to be up to $90 \%$. $^{1}$ The two forms of the virus, HSV-1 and HSV-2, traditionally manifest with orolabial and genital symptoms, respectively; however, anatomical overlap exists. Herpes simplex labialis (HSL) is a painful and incurable condition. The cosmetic appearance, affecting the mouth and lips, results in considerable stigma among the $30 \%$ who suffer from recurrent attacks. ${ }^{2}$

Some HSL episodes are severe and require oral antiviral treatment. However, the

\section{Strengths and limitations of this study}

- One of the largest randomised controlled trials for herpes simplex labialis

- Highly generalisable data from a national cohort.

- We were unable to mask honey treatment.

Lesion progression was not assessed by a clinician

majority are self-limiting and treated with medications such as aciclovir cream. Aciclovir inhibits viral replication within host cells through a series of conversions to aciclovir triphosphate, a competitive inhibitor of viral DNA polymerase. ${ }^{3}$ The topical gold standard for the treatment of HSL for over 20 years, aciclovir is available over-the-counter and there is moderate evidence that it reduces healing time and self-reported pain for HSL attacks. ${ }^{4}$ Novel treatment approaches are needed because of emerging resistance to aciclovir in particular patient groups, ${ }^{5}$ limited risk profiling available (the Food and Drug Administration gives aciclovir a pregnancy category $\mathrm{B}$ rating $)^{6}$ and consumer-driven desire to use complementary and alternative medicines (CAM). ${ }^{7}$

Honey has a long history of therapeutic use, ${ }^{8}$ with an expanding contemporary evidence base, particularly for topical application in wound care, burns and dermatological diseases such as rosacea and HSV. ${ }^{9-12}$ A small pilot study of HSL reported a reduction in healing time from a mean 5.9 days for aciclovir to a mean 2.6 days with topical application of honey. ${ }^{12}$ The mechanisms of a therapeutic benefit for honey could include physiochemical properties such as low $\mathrm{pH}$ and high osmolality and mechanistically independent bioactive factors that vary between honeys; these bioactives may be anti-inflammatory, antiviral and promote wound healing. ${ }^{13-15}$ Kanuka honey is derived from the kanuka tree (Kunzea ericoides) of the same family as the better studied manuka tree 
(Leptospermum scoparium) and has been shown to have immunostimulatory properties in vitro. ${ }^{16}$ The virucidal properties of manuka honey have been demonstrated in preclinical assays, with efficacy against influenza, varicella zoster and rubella viruses. ${ }^{17-19}$ As a member of the same botanical family, Myrtaceae, kanuka-derived honey may offer similar antiviral effects. While the exact factors responsible have yet to be identified, compounds present in honey such as flavonoids have demonstrable antiviral activity; however, further research into the mechanism and clinical relevance is required. ${ }^{20}$

Here, we report a 952-participant randomised controlled trial (RCT) of medical grade, New Zealand kanuka honey cream for the treatment of HSL compared with 5\% aciclovir cream, within a community Pharmacy Research Network. We wished to test the hypothesis based on the available study data ${ }^{12}$ that topical kanuka honey applied to HSL lesions would reduce the healing time to normal skin by at least 1 day compared with topical $5 \%$ aciclovir.

\section{METHODS}

\section{Trial design}

This was a parallel randomised, open-label, active comparator trial in which participants were assigned to either topical medical grade honey or topical $5 \%$ aciclovir cream for the treatment of an active HSL lesion. Participants applied allocated treatment for up to a maximum of 14 days. The primary outcome variable was time from randomisation to complete healing of skin. The trial design, statistical methods and Pharmacy Research Network development have been reported previously. ${ }^{21}$

\section{Setting and participants}

All participants were aged 16 years and over, recruited by a New Zealand-wide network of community pharmacy-based investigators within the first 72 hours from the onset of a new HSL episode. Exclusion criteria were current pregnancy or breast feeding; allergy to honey, bees glycerine or aciclovir; use of antiviral medication for the current cold sore or any oral antiviral medicine during the previous 2 weeks; planned use of additional cold sore medications during the study period; any condition that presented a risk to participant safety or the integrity of the study data. International Conference on Harmonisation Good Clinical Practice guidelines were adhered to for all study procedures and all investigators trained in Good Clinical Practice during the site initiation visit.

\section{Randomisation and blinding}

A biostatistician, blinded to treatment allocation, electronically generated 1:1 randomisation schedules for each uniquely coded study site using a randomisation block of four (Minitab V.13). Allocations were concealed within brown opaque envelopes, opened only at the point of randomisation by an investigator. The study was open-label due to the characteristics of honey rendering masking impossible; therefore, both the pharmacist and the participant were aware of the randomised treatment. The central coordinating study team were blind to allocation at all times unless a safety issue required unmasking of the study physician.

\section{Interventions}

Treatments were $5 \%$ aciclovir cream (Viraban, AFT Pharmaceuticals, Auckland, New Zealand) and 90\% kanuka honey/10\% glycerine cream (Honevo, Honeylab Ltd, Tauranga, New Zealand). Both study groups were instructed to apply their randomised treatment five times daily until the skin returned to normal as per a visual healing chart (figure 1) or 14 days had elapsed, which ever occurred sooner.

\section{Outcome variables}

The primary outcome was healing time from randomisation to normal skin (stage 7). Secondary outcomes were time from randomisation to stage 4 (open wound); time from stage 4 to stage 7; time to pain resolution; highest pain severity on a scale from 0 (no pain) to 10 (severe pain) and acceptability of treatments on a scale from 1 (unacceptable) to 10 (acceptable). Simple data descriptions for median and IQR and minimum to maximum are shown for the continuous variables with counts and proportions for categorical variables, all by randomisation status. An amendment was approved to add time from randomisation to stage 4 (open wound) and time from stage 4 to stage 7 as outcome variables to ensure any stage-dependent benefits to healing were reported.

\section{Data collection}

Following randomisation and dispensing of study treatment, the enrolment Case Report Form was transmitted via eFax with pdf conversion, directly to the coordinating investigators. This information was entered into the study database and a Short Message Service sequencer triggered, which sent 14 unique daily diary hyperlinks to the participant's smart phone at 18:00 hours. Participants self-recorded data for pain, number of applications and the stage of their HSL progression referenced to the seven-stage pictorial chart embedded within the hyperlink (figure 1). Each morning, missing entries for the day prior were screened and participants followed up directly via telephone to ensure real-time data entry. For those participants unable to use the designated study technology, a paper diary was used and sent back to the coordinating centre on completion of the study. A final follow-up contact was conducted via telephone at or on the closest working day to day 15 , with two further attempts up to day 22 if unsuccessful, to record adverse events, concomitant medications and acceptability scoring.

\section{Safety monitoring}

Adverse event data were collected at the follow-up visit and additional contact points during the study period. All were reviewed by the study physician, categorised via a standard severity reporting system and reported to the 


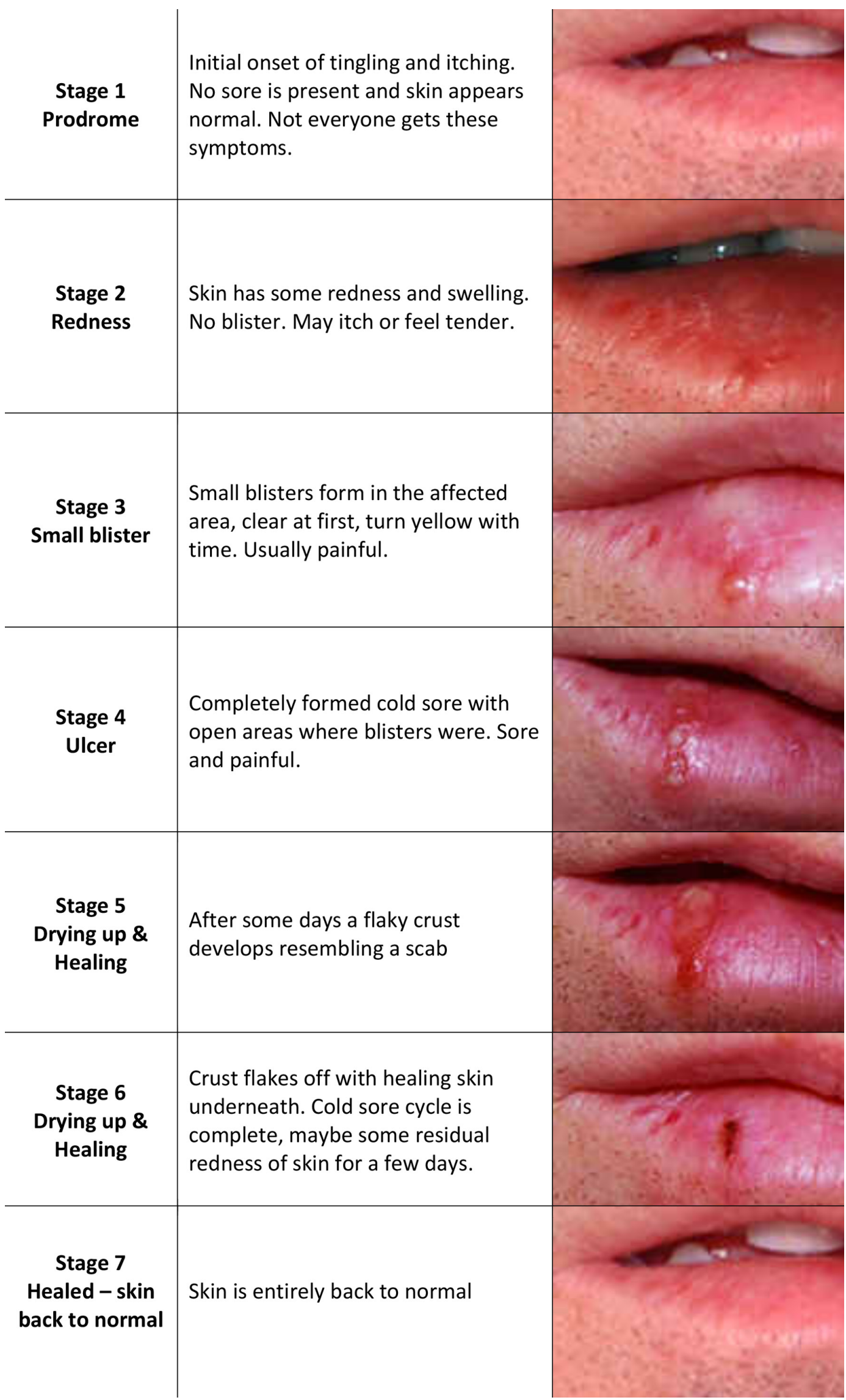

Figure 1 Visual staging chart for HSL progression. Participants recorded the stage of the lesion each evening during the study period within an electronic Case Report Form delivered via Short Message Service hyperlink. The pictorial chart was embedded within this link. All participants were provided a paper back up in case of unavailable technology or systems failure. 
HDEC according to national guidelines. An independent Data and Safety Monitoring Committee convened to review the data of the first 100 participants and recommended the addition of anaphylactic allergy to bee stings be added to the exclusion criteria. This was actioned and approved by the HDEC.

\section{Statistical analysis}

Analysis was intention to treat (ITT). Participants who provided time-to-event data without reaching the end point were included as censored. Participants with no time-to-event data were excluded from the analysis. For the time to outcome variables in days: time to stage 7 , time to stage 4 , time from stage 4 to stage 7 and time to a pain score of zero, Kaplan-Meier plots, associated product limit-based estimates of the median time to event and the HR for the particular event by Cox proportional hazards were used for analyses. An interaction term was used to test if the stage at randomisation affected the response to treatment. A t-test was used to compare the maximum pain scores. The acceptability outcome measure was left skewed and Mann-Whitney test and the Hodges-Lehmann estimator of location were used. The sample size calculation was based on previously reported HRs of 1.23 and 1.24 for a median 5-day duration of symptoms, which implies a 1-day median reduction to 4 days. ${ }^{22}$ Using this assumption of a 5-day median time to healing and clinically significant 1-day median difference in favour of honey, with an associated HR of $1.25,80 \%$ power and $5 \%$ type I error rate, a total of 423 participants were required per arm. Nine hundred fifty in total were to be randomised, to take into account an assumed attrition rate of $10 \%$.

\section{Post hoc analyses}

Post hoc analyses included time from randomisation to stage 6 (loss of crust and residual erythema), in order to benchmark performance with the seminal aciclovir studies, which used this stage of healing as the primary outcome instead of return to normal skin. ${ }^{22}$ In addition, aborted episodes, proportions of HSL episodes not reaching the blistering stage, were estimated, defined by those participants with a baseline stage of 3 or less that progressed to stage 7 without recording 4, 5 or 6 .

SAS V.9.4 was used for analysis.

\section{Patient involvement}

Participants were not involved in the design conduct or interpretation of the study. The main study results will be disseminated to those participants who requested this on enrolment.

\section{RESULTS}

Participants were recruited from 10 September 2015 through to completion on 13 December 2017 within the Pharmacy Research Network, involving 76 community pharmacies across New Zealand. Nine hundred fifty-two participants were randomised to either $5 \%$ aciclovir

\begin{tabular}{|c|c|c|}
\hline \multirow[b]{2}{*}{ Continuous variables } & \multicolumn{2}{|l|}{ Median (IQR) } \\
\hline & Aciclovir, $n=475$ & Honey, $\mathrm{n}=477$ \\
\hline Age (years) & $42(30-54)$ & $43(29-55)$ \\
\hline $\begin{array}{l}\text { Time since last HSL } \\
\text { episode (months) }\end{array}$ & $3(1-7)$ & $3(1-6)$ \\
\hline $\begin{array}{l}\text { Episodes of HSL in } \\
\text { previous year }(\mathrm{N})\end{array}$ & $3(1-5)$ & $3(2-5)$ \\
\hline Pain score at baseline & $2(1-4)$ & $2(1-4)$ \\
\hline $\begin{array}{l}\text { Time from onset } \\
\text { of symptoms to } \\
\text { randomisation (days) }\end{array}$ & $1(0-1)$ & $1(0-1)$ \\
\hline Categorical variables & N/475 (\%) & N/477 (\%) \\
\hline Female sex & 364 (76.6) & $350(73.5)$ \\
\hline \multicolumn{3}{|l|}{ Ethnicity } \\
\hline NZ European & $360(75.8)$ & $354(74.3)$ \\
\hline Māori & $62(13.1)$ & $66(13.8)$ \\
\hline Other & $53(11.1)$ & $57(11.9)$ \\
\hline
\end{tabular}

HSL, herpes simplex labialis.

control $(n=475)$ or honey $(n=477)$. The participants are described in table 1 . The participants had a median of three HSL episodes in the previous year and the median time since the last episode was 3 months.

The flow of participants is shown in figure 2. Four participants in the aciclovir group and one in the honey group were dispensed the incorrect treatment. There were 91 participants lost to follow-up ( 49 aciclovir, 42 honey) and nine withdrew from the study due to adverse events (three aciclovir, six honey). In the final ITT analysis, 852 participants provided data. The 100 participants excluded were defined as those that did not provide any time-to-event data and therefore unable to be included in the survival analysis of the primary outcome variable. All participants that provided data were analysed according to allocation in line with ITT principles.

\section{Primary outcome variable}

There was no evidence of a difference in the time from randomisation to complete healing between aciclovir and honey. The Kaplan-Meier-based estimates $(95 \% \mathrm{CI}$ ) for median healing time were 8 ( 8 to 9 ) days for aciclovir (33 censored) and 9 (8 to 9 ) days for honey (44 censored); HR (95\% CI) 1.06 (0.92 to 1.22), $\mathrm{p}=0.56$ (figure 3A). There was no interaction between the stage at randomisation treated as a continuous variable and randomised treatment $(\mathrm{p}=0.49)$.

\section{Secondary outcome variables \\ Healing time}

The estimated median time from randomisation to stage 4 (open wound) was 2 days for aciclovir (three censored) and 2 days for honey (nine censored); HR (95\% CI) 1.05 (0.92 to 1.20 ), $\mathrm{p}=0.46$ (table 2 , figure $3 \mathrm{~B}$ ). The estimated 


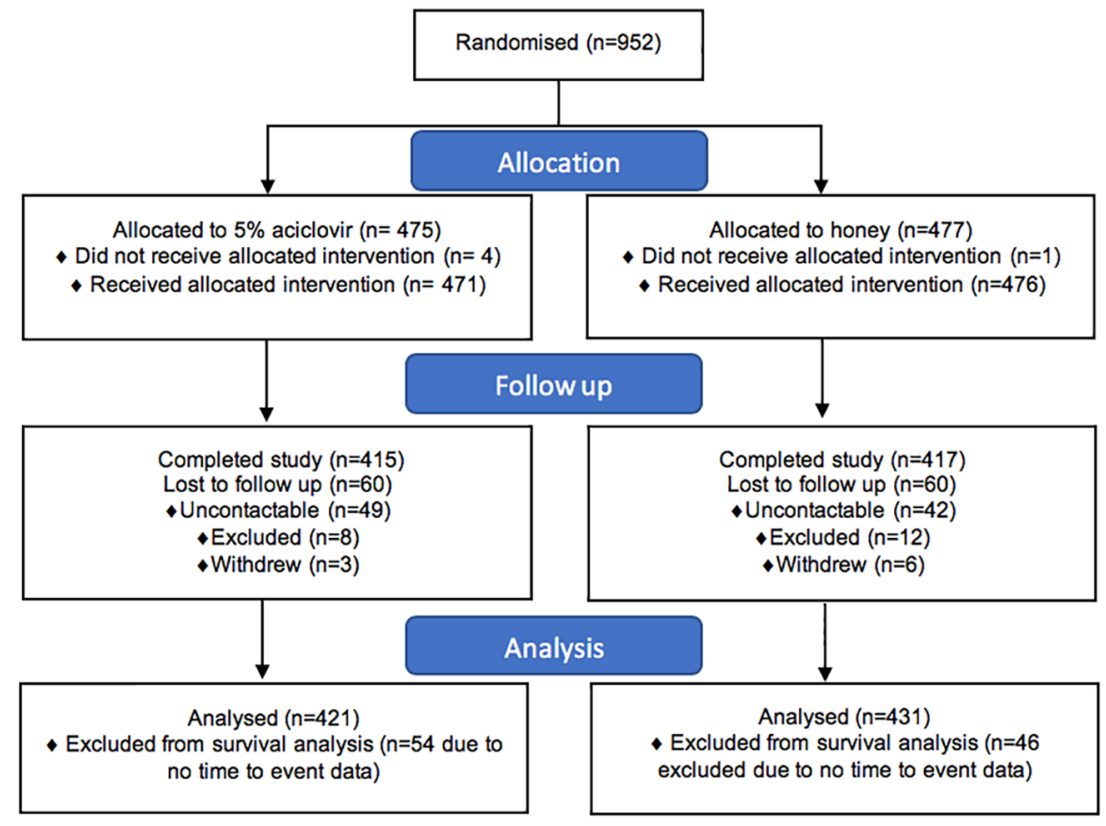

Figure 2 Study CONSORT diagram.

median time from stage 4 to complete healing was 7 days for aciclovir (35 censored) and for honey (40 censored); HR (95\% CI) 1.03 (0.90 to 1.19), $\mathrm{p}=0.66$ (figure 3C).

\section{Pain}

The estimated median time $(95 \% \mathrm{CI})$ to pain resolution was 9 ( 8 to 9 ) days for aciclovir (36 censored) and 9 days (8 to 9) for honey (42 censored); HR (95\% CI) 1.04 (0.91 to 1.20 ), $\mathrm{p}=0.56$ (figure $3 \mathrm{D}$ ). The median (IQR) maximal pain for aciclovir was 3 (2 to 5 ) and for honey 3 (2 to $5)$, with a difference (95\% CI) for aciclovir minus honey -0.02 ( -0.32 to 0.28$), \mathrm{p}=0.90$ (figure $4 \mathrm{~A}$ ).
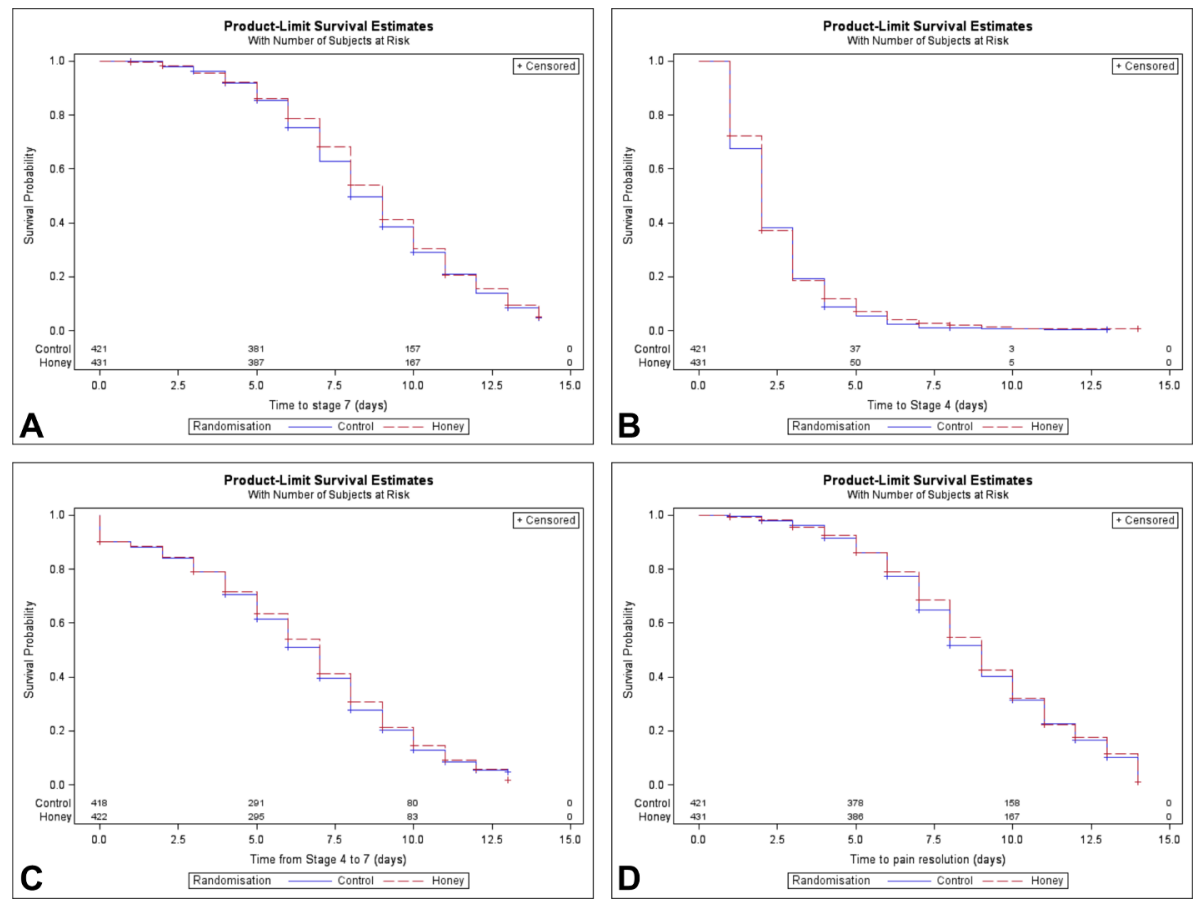

Figure 3 Kaplan-Meier survival plots for: (A) time to stage 7; (B) time to stage 4; (C) time from stage 4 to stage 7; (D) time to pain resolution.
Acceptability

For overall acceptability of treatment, the median (IQR) score for aciclovir was 9 ( 8 to 10$)$ and honey 9 (8 to 10$)$ (figure 4B).

\section{Post hoc analyses}

Healing time to stage 6

There was no difference in estimated median $(95 \% \mathrm{CI})$ time from randomisation to stage 6 (some residual erythema): 5 days ( 5 to 6 ) for aciclovir (seven censored) 
Table 2 Censoring, estimated medians and HRs for all time-to-event outcome variables

\begin{tabular}{|c|c|c|}
\hline Time to stage 7 from randomisation & Control & Honey \\
\hline $\mathrm{N}$ uncensored (censored) & $388(33)$ & 387 (44) \\
\hline \multirow[t]{2}{*}{ Median time to complete healing in days $(95 \% \mathrm{Cl})$} & 8 (8 to 9$)$ & 9 (8 to 9$)$ \\
\hline & HR $(95 \% \mathrm{Cl})$ & $P$ value \\
\hline Aciclovir versus honey & 1.06 (0.92 to 1.22$)$ & 0.56 \\
\hline Time to stage 4 from randomisation & Control & Honey \\
\hline N uncensored (censored) & $418(3)$ & $422(9)$ \\
\hline \multirow[t]{2}{*}{ Median time to stage 4 in days $(95 \% \mathrm{Cl})$} & 2 (not estimable) & 2 (not estimable) \\
\hline & HR (95\% Cl) & P value \\
\hline Control versus honey & 1.05 (0.92 to 1.20$)$ & 0.46 \\
\hline Time from stage 4 to stage 7 & Control & Honey \\
\hline $\mathrm{N}$ uncensored (censored) & $383(35)$ & $382(40)$ \\
\hline \multirow[t]{2}{*}{ Median time from stage 4 to stage 7 in days $(95 \% \mathrm{Cl})$} & 7 (6 to 7$)$ & 7 (6 to 7$)$ \\
\hline & HR $(95 \% \mathrm{Cl})$ & $P$ value \\
\hline Control versus honey & $1.03(0.90$ to 1.19$)$ & 0.66 \\
\hline Time to pain resolution from randomisation & Control & Honey \\
\hline $\mathrm{N}$ uncensored (censored) & $385(36)$ & $389(42)$ \\
\hline \multirow[t]{2}{*}{ Median time to pain resolution in days $(95 \% \mathrm{Cl})$} & 9 (8 to 9$)$ & 9 (8 to 9$)$ \\
\hline & HR (95\% Cl) & $P$ value \\
\hline Control versus honey & 1.04 (0.91 to 1.20$)$ & 0.56 \\
\hline
\end{tabular}

and 5 days ( 5 to 6 ) for honey ( 17 censored); HR (95\% CI) 1.06 (0.93 to 1.22 ), $\mathrm{p}=0.39$ (figure 5 ).

\section{Aborted episodes}

There was no evidence of a difference in the proportions of participants recording stage 3 or less at baseline who reached the primary outcome variable with no recorded stage 4,5 or 6 comprising $43 / 431(10.0 \%)$ in the aciclovir group and $45 / 421(10.7 \%)$ of participants in the honey group; relative risk $(95 \% \mathrm{CI}) 0.93$ (0.63 to 1.39 ), $\mathrm{p}=0.73$.

\section{Adverse events}

There were two serious adverse events deemed unrelated to study treatments, one hospital admission for atrial fibrillation and one hospital admission for urinary retention, and there were 17 adverse events classified as 'definitely/probably/possibly' related to the investigational products, 6 for aciclovir and 11 for honey. These were further subcategorised into pain on application (nil aciclovir, three honey), swelling postapplication (two aciclovir, two honey) and worsening/further cold sores (four aciclovir, six honey).

\section{DISCUSSION}

This study found no difference between the effectiveness of medical grade kanuka honey and topical $5 \%$ aciclovir in the community-based management of HSL. Both treatments had similar efficacy across all outcome variables including time to healing, pain resolution and proportion of aborted episodes between treatment groups. Both treatments were considered highly acceptable by participants.

For the primary outcome variable of time to complete healing, there was no difference between the randomised
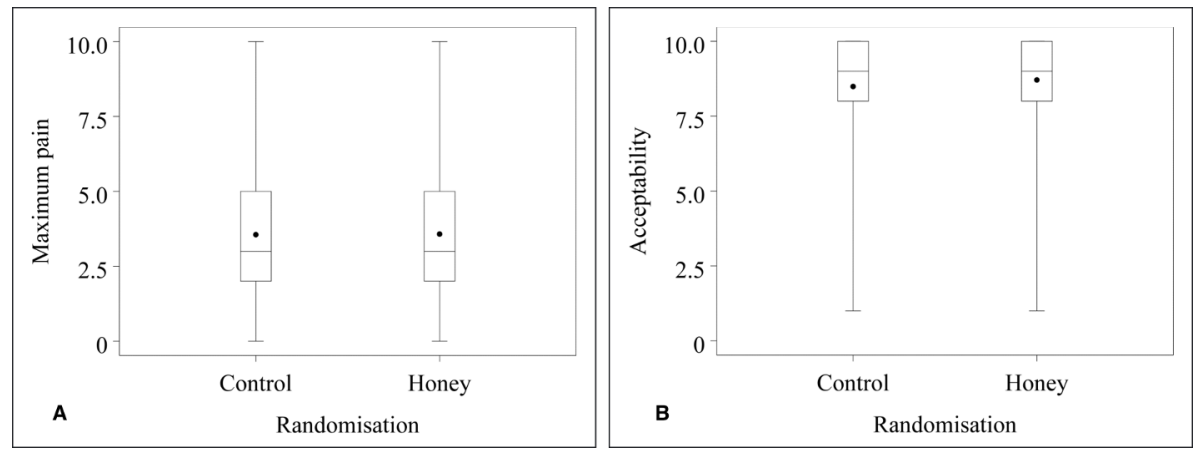

Figure 4 Box plots (A) maximum pain recorded over the study period; (B) treatment acceptability. 


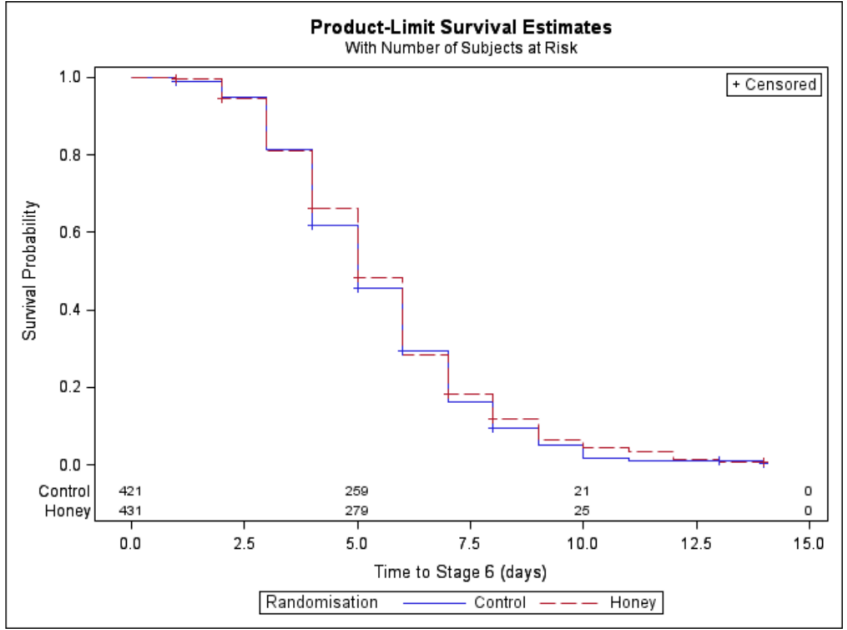

Figure 5 Kaplan-Meier survival plots for time to stage 6.

treatments, with an HR of 1.06. The upper 95\% confidence limit of 1.22 was within the predefined bound of superiority of 1.25 and as such the study had adequate power. Furthermore, the narrow CIs reported here are within the published risk limits in relation to non-inferiority of HSL interventions against $5 \%$ aciclovir. $^{18}$ Although this study was designed to test a superiority hypothesis and we did not specify a non-inferiority bound for formal statistical testing, we consider this study is also consistent with non-inferiority of honey compared with aciclovir. There were five participants (one in the honey group and four in the aciclovir group) that received the incorrect treatment. Given the similar time to recovery for the two treatment arms, it was felt that a per-protocol analysis would not add to the assessment of potential bias in the ITT analysis.

In this study, there was no evidence that honey accelerated healing compared with aciclovir in HSL lesions from stage 4 (ulceration). We had anticipated this might have been the case because of the known positive effects of honey on wound healing processes such as angiogenesis, granulation, epithelialisation, reduction in oedema and debridement. ${ }^{23}$ We had also anticipated that aciclovir may have provided greater early benefit through inhibiting the viral replication process to abort the natural history of the HSL episode. However, this was not supported by our finding that the proportions of lesions between groups that did not progress to the ulcerative stage were similar and interaction analysis for stage of lesion at study baseline provided no evidence that the effect of randomised treatments were dependent on the stage of the HSL lesion at presentation. The estimated pain severity differences had very narrow CIs and were strongly consistent with non-inferiority.

There are a number of statistical considerations relevant to the interpretation of our data. The outcome variables were of a non-normal distribution and thus underwent non-parametric analysis and medians are reported. For time-to-event outcome variables, data from ongoing episodes were censored and incorporated into the survival analysis. The definition of time to healing we used was defined as time to return to normal skin, whereas previous studies have defined this as time to loss of crust, allowing for residual erythema (stage 6 in this study). ${ }^{22}$ For this reason, we performed a post hoc analysis for time from randomisation to stage 6 . This demonstrated a reduction in healing time to this stage, with a median 5 days for both aciclovir and honey.

Our study presents a number of additional strengths in adding to the current evidence base for both topical use of aciclovir and honey for HSL. This appears to be one of the largest single studies of topical aciclovir for $\mathrm{HSL}^{4}$ and provides sufficient power to conclude that there is no difference between aciclovir and honey in terms of a clinically significant difference of 1 day for healing. This large sample size together with the novel study methodology allowed recruitment of a representative New Zealand cohort from 76 pharmacies both within and outside of traditional, usually urban, research centres, mitigating the jurisdiction effect of traditional research models and capturing the heterogeneity for HSL manifestation and progression in the community. ${ }^{24}$ Participants were enrolled at the pharmacist-patient interface when seeking treatment for an active HSL lesion ensuring outcome data represent usual treatment access in the community and avoiding the requirement for pre-randomisation to ensure participants begin study treatment within the prodromal phase. Using smart phone-based diaries containing photographic standards of lesion progression, we were able to both facilitate study participation within usual daily routine, removing the requirement for costly and burdensome clinic visits and maximise chronologically relevant data capture via immediate follow-up of missed entries. These factors provide valuable information as to the generalisability of traditional RCT models assessing HSL which, while providing essential safety, efficacy and regulatory data, are unable to definitively measure drug performance in the highly diverse real-world setting. ${ }^{25}$

There was no provision to mask the allocation of honey to participants; therefore, the consenting pharmacist investigators and participants were unblinded to treatment allocation. This may be considered a potential source of bias however, unavoidable in the context of investigational product and setting, and interestingly, there is no established evidence that participants alter their self-reported data dependent on knowledge of the treatment they are receiving. ${ }^{26}$

Importantly, we have demonstrated the feasibility of conducting a large-scale comparative RCT utilising a cost-effective, regulatory compliant and time-efficient community-based infrastructure, while maintaining robust outcome data. This provides significant opportunity to enhance the evidence base for non-prescribed medications such as CAM by overcoming the limitations of cost-prohibitive traditional models. ${ }^{27}$

These findings suggest that medical grade kanuka honey may be employed as an equivalent therapeutic 
choice to aciclovir cream, for the treatment of HSL, particularly given the emergent issues of drug resistance $^{5}$ and the needs of particular patient groups that may be unable to use current pharmacological therapies due to allergy and lack of safety data in pregnancy and breast feeding. While our study does not replicate the apparent superiority of honey over acyclovir cream demonstrated in a clinical pilot study of $2004,{ }^{12}$ there are a number of notable differences and possible explanations for this. Methodologically, the studies are very different, with a very small sample size in the pilot and use of physician-scored lesions compared with patient-reported outcomes in our study. While different honeys share common physicochemical properties, there can be significant variations in their bioactive profiles. ${ }^{28}$ The multifloral honey used in the aforementioned pilot study and sourced from the United Arab Emirates will therefore show a very different composition profile to New Zealand kanuka honey, potentially conferring superior antiviral and wound promoting immunostimulatory effects, which led to the decreased time to healing reported. Further understanding of the factors responsible for such effects and improved and standardised analysis techniques will allow for better correlation between composition and the clinical effects of different honeys.

The priority now is to investigate whether honey in combination with either aciclovir or other natural antiviral compounds ${ }^{29}$ might have greater efficacy than individual components in the topical management of HSL and whether medical grade honey might have similar efficacy and acceptability in paediatric HSL, a group from which we received much guardian-led interest during the study period. Investigation of the efficacy of medical grade honey in other herpetic indications such as herpes zoster is also warranted.

\section{CONCLUSIONS}

Prior RCTs provide evidence that topical application of aciclovir reduces time to healing and pain resolution in HSL and as such is used as a gold standard front-line topical therapy, globally. The study findings suggest therapeutic equivalence of medical grade Kanuka honey with aciclovir in the treatment of HSL, when used in routine community treatment at the pharmacy interface. This provides rationale for the recommendation of topical honey for HSL management as an acceptable alternative to aciclovir cream.

Acknowledgements We would like to thank the study participants, pharmacybased investigators and the Pharmacy Guild of New Zealand in the conduct of the study and establishing the wider Pharmacy Research Network.

Collaborators Abbie Copinga, Abigail Cadwallader, Ahmad Zareh, Aidan Kortegast, Al-Sheibani Saif, Alaina Van Zyl, Alex Graham, Alice Liu, Alice Manch, Alison van Wyke, Amanda Barkley, Amy Zhuang, Andrew McGlashen, Androulla Kotrotsos, Angela Blackwood, Angela Liu, Angeline Day-Mesuré, Annabel Turley, Anne Lim, Anne Marie-Nimmo, Anstey Harsant, Anthony Roberts, Ashley Cronin, Barbara McRae, Blair Finlayson, Bob Kim, Brandon, Brendon McIntosh, Brian Johnston, Carina Soeteman, Carla Mclnness, Carrol Newman, Cassie Butler, Catherine Hosler, Cathy Hight, Chantel Kissick, Charlotte Schimanski, Chau Ly, Cheryl Mabbett, Chris
Wrapson, Christy Biju, Chuck Varghese, Claire Livingston, Corry Bezems, Danielle Stewart, Daryl Sayer, David Postlewaight, Deb Lawrence, Debora Ngny, Deborah Ellison, Debra Clutterback, Delphine Destrez, Diana Montelli, Dipika Parmar, Dixie Howard, Donnie Loh, Eddie See, Elda Lubbe, Eric Li, Evan Tan, Fiona McLachlan, Fiona Srush, Fran Chen, Garth Mitchinson, Gina Azer-Iskander, Glenn Summerville, Grace 0'Conner, Grant Bell, Hayley Garvin, Helen Jarvie, Henriette Meyer, Ingrid Nickson, Ingrid Reed, Irene Nicks, Jackie Jamieson, Jacqui Brus, Jacqui Craw, James Westbury, Jan Green, Janet Downing, Jayne Lewis, Jenna Ludlow, Jenni Puckley, Jennifer Gerbes, Jenny Sparks, Jenny Wu, Jess Barton, Jessica Ensor, Jilly Alexander, Jim Sherborne, Joanna Topliss, Jordan Jeffray, Jordon Hinton, Joseph Tsou, Joy Birch, Julia McDonald, Julie Earwaker, Julie Lamb, Julie Summers, Kadyn Lowe, Kaleigh Mackel, Karen Rich, Karen Chen, Karen Rich, Karen Wainman, Karena Hall, Kate Adams, Kate Griffin, Kayleigh Mackel, Kelly Burgess, Kelly Harvey, Kelly Shearer, Kelsi Burns, Kerry Dean, Kerry Oxenham, Kritika Singh, Lara Blaikie, Leanne Hall, Leanne Herbert, Leanne Hosking, Leanne Steele, Leigh Vaughan, Lesley Robertson, Levi Bian, Linda Herman, Linda Joe, Linda Southby, Lisa Josephs, Lisa Mitchell, Lorina Lu, Lorraine Brunton, Lucy Armstrong, Lynda Bell, Malinda Ouk, Malli Kotali, Marcus Liddle, Margaret Helms, Marion Gray, Mark Arundel, Mark Webster, Martin Boyle, Maryanne Smyth, Mate Hegedus-Gaspar, Matthew Grey, Maureen Raju, Melanie Wong, Michelle Hwang, Michelle Nawisielski, Michelle Speirs, Natascha Roughton, Navjot Kaw, Neha Chand, Nehad Kamel, Neville Puckey, Nicholas Tee, Nimmi Gnanasekaran, Nolan McRae, Noor Al-Rawe, Oliver Rew, Olivia Haslam, Outi Kolju, Palak Mehta, Patrick Lim, Peter Neal, Rachael Gerretzen, Rachael Munns, Rachel Yang, Rachelle Smith, Raksha Goundar, Rav Singh, Ravniel Singh, Rebecca Coley, Rebecca Hesom, Rebekah Beard, Reece Olsen, Renee Belling, Robyn Morrison, Roseanna McDonald, Ruby Willing, Saif Al-Sherbeni, Sally Purdie, Sam Betty, Sam Appleford, Samantha Fordham, Samit Patel, Sara Preston, Sarah Wallace, Sascha Ion, Shahlaa Al Salih, Sharon Sullivan, Shazeel Rauf, Sheryl Montgomerie, Shilpa Narain, Shirin Namjou, Shuji Zhang, Simerjeet Singh, Sjaani Stanley, Sonia Schwaum, Steve Jo, Sultana Zannat, Tanya Baker, Tyler Pornchaisuksiri, Utsav Sharma, Vicki Douglas, Victoria Rameke, Vincent Ho, Vioky Usher, Violet Harley, Vishwatej Gangapuri, Warren Greene, Wendy Parkes, William Gia, Wilma Gordon, Yalun Weng, Yasmin Razoki, Yolanda Savage, Zheng Li.

Contributors AS, RB, IB, MW and MMcC conceived and designed the study and protocol. AS and JS recruited, trained and formalised the Pharmacy Research Network. AS, JS, NS and DT managed the study and data. MW analysed the final data set. AS and RB drafted the final manuscript. AS is the guarantor. All authors read and approved the final manuscript.

Funding This study was funded by Honeylab Ltd, Tauranga New Zealand.

Competing interests RB reports grants from HoneyLab, during the conduct of the study; grants and personal fees from GlaxoSmithKline, outside the submitted work. All other authors declare: no support from any organisation for the submitted work; no financial relationships with any organisations that might have an interest in the submitted work; no other relationships or activities that could appear to have influenced the submitted work.

Ethics approval Approval from both the Health and Disability Ethics Committee (HDEC) (Northern B ref: 15/NTB/93) and Standing Committee of Therapeutic Trials (15/SCOTT/14) was obtained.

Provenance and peer review Not commissioned; externally peer reviewed.

Data sharing statement All data relevant to the study are included in the article or uploaded as supplementary information.

Open access This is an open access article distributed in accordance with the Creative Commons Attribution Non Commercial (CC BY-NC 4.0) license, which permits others to distribute, remix, adapt, build upon this work non-commercially, and license their derivative works on different terms, provided the original work is properly cited, appropriate credit is given, any changes made indicated, and the use is non-commercial. See: http://creativecommons.org/licenses/by-nc/4.0/.

\section{REFERENCES}

1. Wald A, Corey L. Persistence in the population: epidemiology, transmission. In: Arvin A, Campadelli-Fiume G, Mocarski E, eds. Human Herpesviruses: Biology, Therapy, and Immunoprophylaxis. Cambridge: Cambridge University Press, 2007

2. Donigan JM, Pascoe VL, Kimball AB. Psoriasis and herpes simplex virus are highly stigmatizing compared with other common dermatologic conditions: A survey-based study. J Am Acad Dermatol 2015;73:525-6. 
3. James SH, Prichard MN, Mené Ndez-Arias L. Current and future therapies for herpes simplex virus infections: mechanism of action and drug resistance. Curr Opin Virol 2014;8:54-61.

4. Worrall G, labialis H, Evid C. Herpes labialis. Clin Evid 2009;2009 http://www.ncbi.nlm.nih.gov/pubmed/21726482

5. Frobert E, Burrel S, Ducastelle-Lepretre S, et al. Resistance of herpes simplex viruses to acyclovir: an update from a ten-year survey in France. Antiviral Res 2014;111:36-41.

6. Patel VM, Schwartz RA, Lambert WC. Topical antiviral and antifungal medications in pregnancy: a review of safety profiles. J Eur Acad Dermatol Venereol 2017;31:1440-6.

7. Frass M, Strassl RP, Friehs $\mathrm{H}$, et al. Use and acceptance of complementary and alternative medicine among the general population and medical personnel: a systematic review. Ochsner $J$ 2012;12:45-56.

8. Eteraf-Oskouei T, Najafi M. Traditional and modern uses of natural honey in human diseases: a review. Iran J Basic Med Sci 2013:16:731-42.

9. Jull AB, Cullum N, Dumville JC, et al. Honey as a topical treatment for wounds. Cochrane Database Syst Rev 2015;2015:16-92.

10. Wijesinghe $\mathrm{M}$, Weatherall $\mathrm{M}$, Perrin $\mathrm{K}$, et al. Honey in the treatment of burns: a systematic review and meta-analysis of its efficacy. $N Z$ Med J 2009;122:17-24.

11. Braithwaite I, Hunt A, Riley J, et al. Randomised controlled trial of topical kanuka honey for the treatment of rosacea. BMJ Open 2015:5:e007651.

12. Al-Waili NS. Topical honey application vs. acyclovir for the treatment of recurrent herpes simplex lesions. Med Sci Monit 2004;10:MT94-8.

13. Majtan J. Honey: An immunomodulator in wound healing. Wound Repair and Regeneration 2014;22:187-92.

14. Molan P, Rhodes T. Honey: a biologic wound dressing. Wounds 2015;27:141-51.

15. Hashemipour MA, Tavakolineghad Z, Arabzadeh SA, et al. Antiviral activities of honey, royal jelly, and acyclovir against HSV-1. Wounds 2014;26:47-54

16. Gannabathula S, Skinner MA, Rosendale D, et al. Arabinogalactan proteins contribute to the immunostimulatory properties of New Zealand honeys Arabinogalactan proteins contribute to the immunostimulatory properties of New Zealand honeys. 2012;3973.
17. Watanabe K, Rahmasari R, Matsunaga A, et al. Anti-influenza viral effects of honey in vitro: potent high activity of manuka honey. Arch Med Res 2014;45:359-65

18. Shahzad A, Cohrs RJ. In vitro antiviral activity of honey against varicella zoster virus (VZV): A translational medicine study for potential remedy for shingles. Trans/ Biomed 2012;3:1-5.

19. Zeina B, Othman O, al-Assad S. Effect of honey versus thyme on Rubella virus survival in vitro. J Altern Complement Med 1996;2:345-8.

20. Zakaryan $\mathrm{H}$, Arabyan $\mathrm{E}$, Oo A, et al. Flavonoids: promising natural compounds against viral infections. Arch Virol 2017;162:2539-51.

21. Semprini A, Singer J, Shortt N, et al. Protocol for a randomised controlled trial of $90 \%$ kanuka honey versus $5 \%$ aciclovir for the treatment of herpes simplex labialis in the community setting. BMJ Open 2017;7:e017766

22. Spruance SL, Nett R, Marbury T, et al. Acyclovir cream for treatment of herpes simplex labialis: results of two randomized, double-blind, vehicle-controlled, multicenter clinical trials. Antimicrob Agents Chemother 2002;46:2238-43.

23. Majtan J. Honey: an immunomodulator in wound healing. Wound Repair Regen 2014;22:187-92.

24. Gheorghe A, Roberts T, Hemming K, et al. Evaluating the Generalisability of Trial Results: Introducing a Centre- and Trial-Level Generalisability Index. Pharmacoeconomics 2015;33:1195-214.

25. Rothwell PM. External validity of randomised controlled trials: "to whom do the results of this trial apply?". Lancet 2005;365:82-93.

26. Atkinson TM, Wagner JS, Basch E. Trustworthiness of PatientReported Outcomes in Unblinded Cancer Clinical Trials. JAMA Onco 2017;3:738-9.

27. Sertkaya A, Wong HH, Jessup A, et al. Key cost drivers of pharmaceutical clinical trials in the United States. Clin Trials 2016;13:117-26

28. Salonen A, Virjamo V, Tammela P, et al. Screening bioactivity and bioactive constituents of Nordic unifloral honeys. Food Chem 2017;237:214-24.

29. Lin LT, Hsu WC, Lin CC. Antiviral natural products and herbal medicines. J Tradit Complement Med 2014;4:24-35. 